\begin{tabular}{|c|c|}
\hline$A$ & $\begin{array}{c}\text { International Journal of Current Research } \\
\text { and Academic Review }\end{array}$ \\
\hline & $\begin{array}{c}\text { ISSN: 2347-3215 (Online) }, ; \text { Volume } 5 \\
\text { Journal homepage: http://www.ijcrar.com } 7 \text { (July-2017) }\end{array}$ \\
\hline
\end{tabular}

doi: https://doi.org/10.20546/ijcrar.2017.507.009

\title{
Zinc Supplementation Significantly Improves Neurophysiological and Glycemic Measures in Patients with Diabetic Neuropathy
}

\author{
Sumana Gupta ${ }^{1 *}$ Indira Maisnam ${ }^{2}$, Tapobrata Guharay ${ }^{3}$, Sandip Ghosh ${ }^{4}$, \\ Apurba Kumar Mukherjee ${ }^{5}$ and Anil Baran Singha Mahapatra ${ }^{1}$
}

${ }^{I}$ Department of Physiology, R. G. Kar Medical College, Kolkata, West Bengal, India

${ }^{2}$ Department of Endocrinology, R. G. Kar Medical College, Kolkata, West Bengal, India

${ }^{3}$ Department of Community Medicine, R. G. Kar Medical College, Kolkata, West Bengal, India

${ }^{4}$ Department of Cardiology, R. G. Kar Medical College, Kolkata, West Bengal, India

${ }^{5}$ Department of General Medicine, R. G. Kar Medical College, Kolkata, West Bengal, India

*Corresponding author

\begin{abstract}
Though tight glycemic control remains the cornerstone for prevention and management of Diabetic Neuropathy (DN), it is often inadequate. Zinc supplementation may offer symptomatic and functional improvement in these patients. We tried to evaluate the effects of zinc supplementation on Nerve Conduction Study (NCS) parameters and glycosylated hemoglobin (HbA1c) level in patients with DN and search for whether duration of diabetes affect outcome. Patients of type 2 diabetes mellitus (T2DM) with peripheral neuropathy, presenting at Diabetes clinic were enrolled for baseline and follow-up (after 12 weeks) evaluation of NCS parameters along with HbA1c for Cases (received zinc therapy $100 \mathrm{mg} / \mathrm{day}$ ) and Controls (did not receive zinc). Cases divided into three groups according to diabetes duration and evaluated for any significant differences in the response to the zinc, reflected by NCS parameters and HbA1c. The observational follow-up study on 45 patients showed highly significant $(\mathrm{p}<0.01)$ improvement for Median and Tibial motor amplitude, Median sensory (amplitude, velocity) and Sural (latency, amplitude) after 12 weeks of zinc supplementation in Cases. Significant difference $(\mathrm{p}<0.05)$ in changes was seen among Cases $(n=25)$ compared to Controls $(\mathrm{n}=20)$ in amplitude and velocity (motor parameters) and latency, amplitude, velocity (sensory parameters) along with HbA1c. Median motor latency and $\mathrm{HbAlc}$ level, after zinc therapy varied significantly in individuals with longest diabetes duration.
\end{abstract}

\section{Article Info}

Accepted: 02 July 2017

Available Online: 20 July 2017

\section{Keywords}

Nerve conduction study, Diabetic neuropathy, Zinc,

$\mathrm{HbAlc}$

\section{Introduction}

Diabetes mellitus (DM) is the most common metabolic disorder in the world. The International Diabetes Federation predicts that 642 million people will have diabetes by 2040 . Most of the morbidity and mortality in diabetes are due to its chronic complications. Diabetic neuropathy (DN) is one of the most common and troublesome of all diabetes complications. It is defined as the presence of symptoms and/or signs of peripheral 
nerve dysfunction in people with diabetes after exclusion of other causes. DN occurs in 50\% of patients with underlying type 1 and type 2 diabetes mellitus. Long diabetes duration and poor glycemic control correlates with neuropathic symptoms. The most common form of DN is distal symmetric polyneuropathy, in which the peripheral nerves are affected in a length dependent pattern with a predilection for early involvement of the longest axons of the somatic motor or sensory nerves beginning in the feet with proximal progression (Thomas and Eliasson, 1984). Sensory neuropathy, foot deformity arising from motor neuropathy, autonomic neuropathy and Charcot's foot place the foot in diabetes at high risk.

Patients with T2DM have insulin resistance, hyperinsulinaemia, $\beta$-cell dysfunction with subsequent $\beta$-cell failure (Stumvoll et al., 2005). At high concentrations, insulin is organized as hexamers with two atoms of zinc. Zinc plays an important role in the synthesis, storage and also secretion of insulin (Chausmer, 1998). Decreased zinc levels affect ability of islet cells to produce and secrete insulin. Previous workers found lower blood zinc levels in diabetes (Khandelwal et al., 1981; Isbir et al., 1994; Garg et al., 1994).

Nerve conduction studies (NCS) are the gold standard for detection and follow-up of neuropathies, including DN. Clinical studies found that zinc supplementation reduces DN severity and helps improving glycemic control (Gupta et al., 1998; Hayee et al., 2005; Jayawardena et al., 2012). In studies where subjects received high doses of zinc (660 $\mathrm{mg} /$ day), none explored two important parameters of NCS, latency and amplitude (Gupta et al., 1998; Hayee et al., 2005). This study also tried to determine if diabetes duration had any impact on the response to zinc therapy in $\mathrm{DN}$ as assessed by NCS and HbA1c level.

\section{Materials and Methods}

An observational longitudinal follow-up study was conducted in the Department of Physiology of R.G. Kar Medical College and Hospital, Kolkata from October 2015 to September 2016 after proper ethical clearance. 56 T2DM patients between 18 to 65 years with subjective and objective evidence of peripheral neuropathy were recruited from Diabetic Clinic.

Among 56 patients, 28 received zinc supplementation $(100 \mathrm{mg} /$ day) for 12 weeks along with their usual care from diabetes Out Patient Department (OPD) of our hospital. They were termed Cases. Remaining 28 patients not receiving zinc supplementation but receiving their usual care were labelled Controls. Informed consent was taken from all patients. After baseline evaluation of symptoms, signs and HbA1c, baseline NCS study was performed in the Neurophysiology Laboratory of the Department of Physiology on all the patients.

After 12 weeks, patients were subjected to NCS studies again. Out of 56 patients, 45 patients (25 Cases and 20 Controls) attended for follow-up evaluation by NCS, the remaining were lost to follow-up.

The 25 Cases were divided into three groups according to DM duration ( Gr 1, Gr 2 and Gr 3 with diabetes duration $<5,5$ to 10 and $>10$ years respectively).

Patients with type 1 diabetes mellitus, nephrotic syndrome, chronic diarrhea, malignancy, acute illness, history of dyspepsia and gastrointestinal irritation, patients on multivitamin treatment, pregnant ladies, alcohol abuse and patients with chronic renal failure stage 3 to 5 were excluded from the study.

Detailed history, including duration of disease and treatment, subjective symptoms of neuropathy like tingling, numbness and paresthesia were noted. General physical examination along-with comprehensive foot examination and clinical examinations for objective neuropathy were done.

Patients underwent examination with a 10-g monofilament; tests for joint sense, touch and pain sensation; vibration test; examination for muscle wasting and power; and reflexes.

Follow-up value of HbA1c after 12 weeks was noted in all.

Baseline NCS for Median (motor and sensory), Tibial (motor) and Sural (sensory) was done using RMS EMGEP, MARK-2, 2011, computerized machine. Distal motor latency (DML), Compound muscle action potential (CMAP), Motor nerve conduction velocity (MNCV) for motor nerves and Distal sensory latency (DSL), Sensory nerve action potential (SNAP), Sensory nerve conduction velocity (SNCV) were noted for sensory components.

The data was summarized and results were analyzed by Microsoft Excel (2016), IBM-SPSSv20. The means of Cases and Controls were compared by paired t test (baseline and follow up values), unpaired t test (values 
that followed normal distribution), Wilcoxon signed rank test, Kruskal Wallis and Mann Whitney test (values that did not follow normal distributions). Values of each subgroup of Cases were further compared by ANOVA and Post-hoc analysis.

\section{Results and Discussion}

A total of $(n=45)$ patients (25 Cases and 20 Controls) with DN were available for analysis. Mean age of the study population was $(51.32 \pm 8.93)$ years in Cases and $(49.35 \pm 8.62)$ years in Controls.

Of 25 Cases 13 (52\%) had diabetes for less than 5 years [Gr1], $8(32 \%)$ had disease for 5-10years [Gr2], and rest $4(16 \%)$ had DM for $>10 y e a r s$ [Gr3].

The baseline characteristics of different NCS parameters (motor and sensory) and glycemic status (HbA1c) were comparable between Cases and Controls (Table1).

There was significant improvement ( $\mathrm{p}$ value $<0.05$ ) in NCS parameters [CMAP of Median and Tibial, Median sensory parameters (SNAP, SNCV) and (Sural DSL, SNAP)] among Cases after 12 weeks of zinc supplementation compared with their baseline values, though the HbA1c value in Cases did not differ significantly at 12 weeks follow up compared to their baseline (Table 2).

Change (increase or decrease) of each NCS parameter and $\mathrm{HbA} 1 \mathrm{c}$ level from baseline to follow-up values in Cases and Controls were calculated and compared.

Statistically significant ( $\mathrm{p}$ value $<0.05$ ) improvement of NCS parameters (CMAP of Median and Tibial, MNCV of Median, SNAP and SNCV of Median and DSL, SNAP and SNCV of Sural) along with HbA1c level was seen among Cases individuals compared to Controls (Table 3; Figure 1).

The changes (increase or decrease) of each NCS parameter and $\mathrm{HbA} 1 \mathrm{c}$ level from baseline to follow-up values among individuals of three groups of Cases ( $\mathrm{Gr} 1$, $\mathrm{Gr} 2$ and Gr3) were compared (Table 4A, 4B).

There was a statistically significant difference ( $p$ value $<0.05$ ) only for Median DML along with $\mathrm{HbA} 1 \mathrm{c}$ between Groups 1, 2 and 3 in the Cases (Table 4A).
Significant differences within groups were shown by Post-hoc analysis (Table 4B).

When we compared the baseline and follow-up values of different NCS parameters in Cases, statistically highly significant improvement was found for CMAP Median $(\mathrm{p}<0.001)$, CMAP Tibial $(\mathrm{p}=0.001)$, Median SNAP $(p<0.001)$, SNCV $(p=0.003)$, Sural DSL $(p=0.019)$ and $\operatorname{SNAP}(\mathrm{p}<0.001)$.

Baseline values of CMAP Median and Tibial, Median SNAP, SNCV, Sural DSL and SNAP $(3.94 \pm 2.54) \mathrm{mv}$, $(3.07 \pm 3.26) \mathrm{mv}, \quad(17.27 \pm 12.39) \mu \mathrm{v}, \quad(40.73 \pm 12.41) \mathrm{m} / \mathrm{s}$, $(5.84 \pm 1.66) \mathrm{ms}, \quad(4.38 \pm 1.24) \mu \mathrm{v}$ improved to $(10.05 \pm 4.34) \mathrm{mv}, \quad(7.12 \pm 4.79) \mathrm{mv}, \quad(32.11 \pm 18.20) \mu \mathrm{v}$, $(46.42 \pm 11.28) \mathrm{m} / \mathrm{s}, \quad(4.85 \pm 1.30) \mathrm{ms}, \quad(7.36 \pm 3.69) \quad \mu \mathrm{v}$ respectively (Figure 2 ).

MNCV of Median in Cases also improved from its baseline value $(49.47 \pm 8.39) \mathrm{m} / \mathrm{s}$ to $(52.41 \pm 7.27) \mathrm{m} / \mathrm{s}$, though this change was statistically not significant $(\mathrm{p}>0.05)$.

Analysis of the difference in values (increase or decrease) of different NCS parameters from baseline to follow-up in Cases and Controls showed that there was significant increment of CMAP Median $(p<0.001)$, CMAP Tibial $(p<0.001)$, MNCV Median $(p=0.035)$, Median SNAP $(p<0.001)$, Median SNCV $(p=0.001)$, Sural SNAP $(p<0.001)$, Sural SNCV $(p=0.013)$ and statistically significant decrement of Sural DSL $(\mathrm{p}=0.002)$ in Cases compared to Controls.

Thus there was improvement in the neurophysiological findings in DN after zinc therapy in Cases. When we classified the Cases into three groups according to diabetes duration and evaluated their response to zinc, it was seen that there was significant difference in decrement of only Median DML ( $\mathrm{p}=0.001)$.

The Change in Median DML (12 week value-baseline= $\Delta$ Med DML) was $0.27 \pm 0.53,-0.33 \pm 0.47$ and $-1.9 \pm 1.85$ in Groups 1, 2 and 3 respectively, thereby showing the best response in Group3, followed by group 2 and 1 respectively. $\mathrm{T}$

hus individuals with longest diabetes duration had the best improvement in Median DML. 
Fig.1 Comparison between change of values of NCS parameters and HbA1c among cases and controls

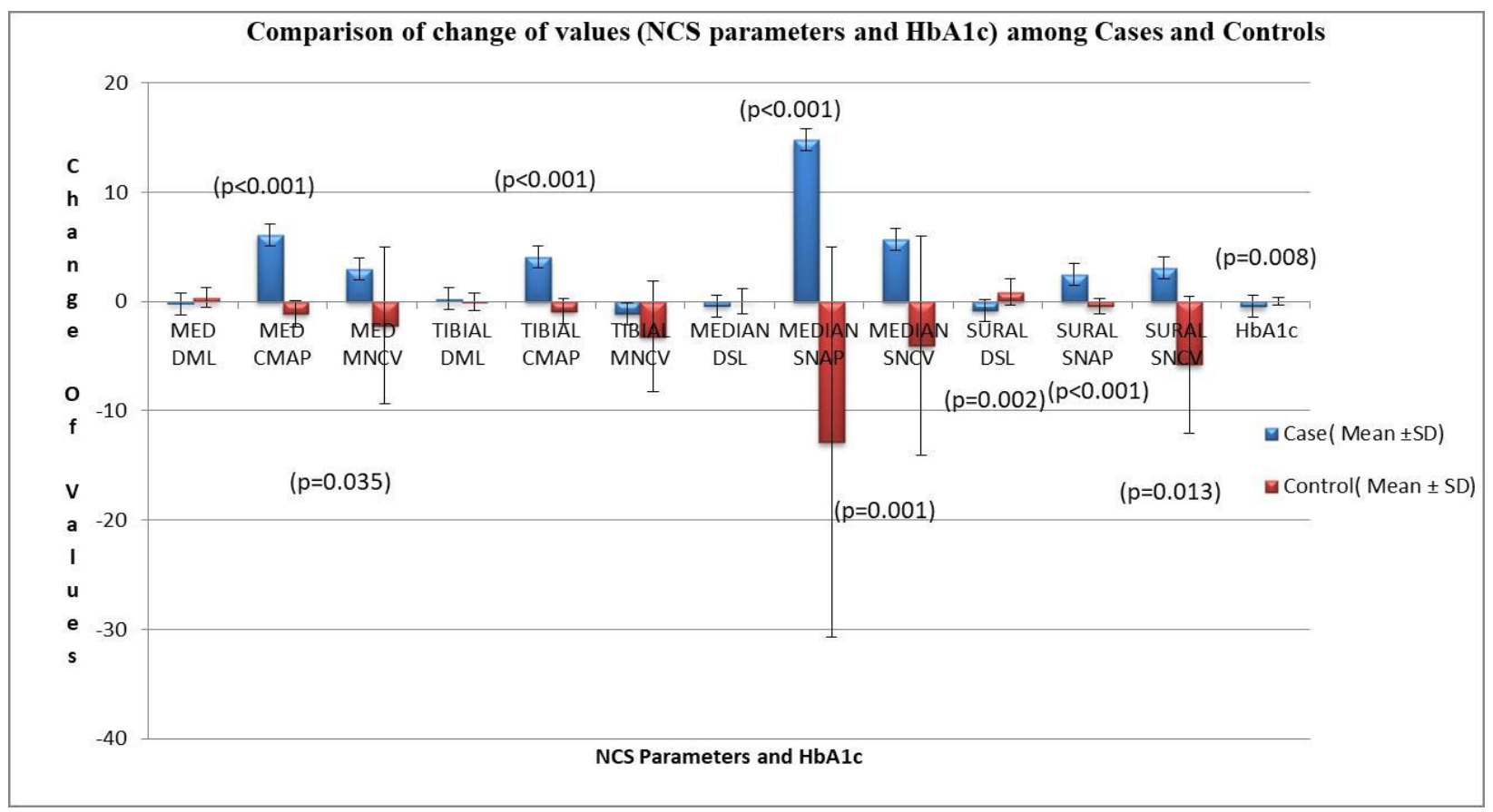

Fig.2 Tracing of Median SNC recording before (A) and after (B) zinc therapy and Tibial MNC recording before (C) and after (D) zinc therapy in cases

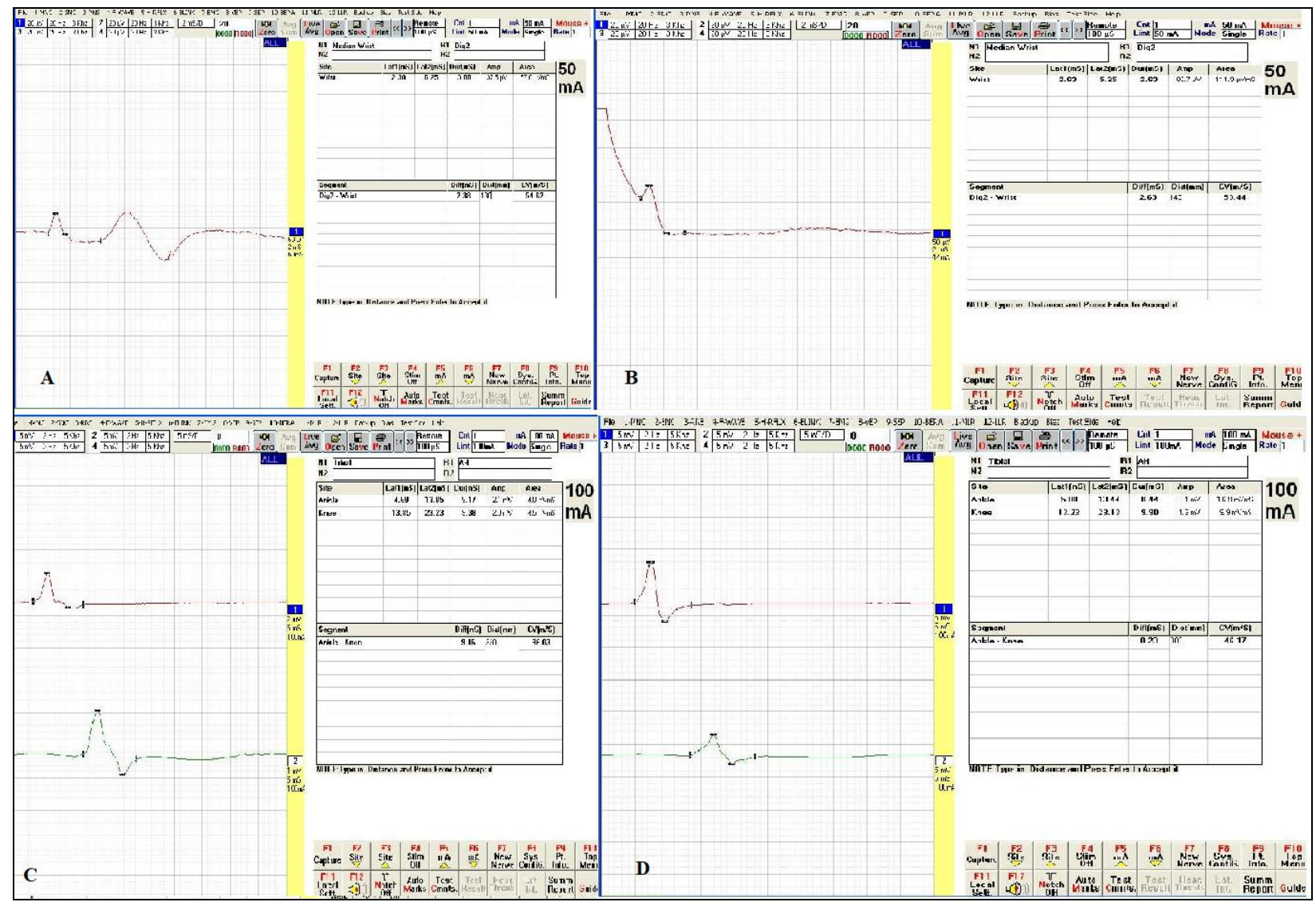


Table.1 Baseline values of HbA1c and NCS parameters among cases and controls

\begin{tabular}{|c|c|c|c|c|}
\hline \multicolumn{2}{|c|}{ Parameters } & $\begin{array}{c}\text { Baseline values in Cases } \\
\left(\text { Mean } \pm \text { SD }^{\mathbf{g}}\right)\end{array}$ & $\begin{array}{c}\text { Baseline values in Controls } \\
\left(\text { Mean } \pm \mathbf{S D}^{\mathrm{g}}\right)\end{array}$ & p Value \\
\hline \multicolumn{2}{|c|}{ Glycemic status(HbA1c) } & $7.51 \pm 1.66$ & $7.94 \pm 1.31$ & 0.445 \\
\hline \multirow{3}{*}{ MEDIAN } & $\mathrm{DML}^{\mathrm{a}}$ & $(3.99 \pm 1.34) \mathrm{ms}$ & $(4.13 \pm 1.29) \mathrm{ms}$ & 0.223 \\
\hline & $\mathrm{CMAP}^{\mathrm{b}}$ & $(3.94 \pm 2.54) \mathrm{mv}$ & $(5.87 \pm 2.92) \mathrm{mv}$ & 0.328 \\
\hline & $\mathrm{MNCV}^{\mathrm{c}}$ & $(49.47 \pm 8.39) \mathrm{m} / \mathrm{s}$ & $(51.33 \pm 7.95) \mathrm{m} / \mathrm{s}$ & 0.454 \\
\hline \multirow{3}{*}{ TIBIAL } & $\mathrm{DML}^{\mathrm{a}}$ & $(5.18 \pm 0.90) \mathrm{ms}$ & $(5.42 \pm 0.85) \mathrm{ms}$ & 0.447 \\
\hline & CMAP $^{b}$ & $(3.07 \pm 3.26) \mathrm{mv}$ & $(3.31 \pm 2.18) \mathrm{mv}$ & 0.357 \\
\hline & $\mathrm{MNCV}^{\mathrm{c}}$ & $(41.49 \pm 8.74) \mathrm{m} / \mathrm{s}$ & $(41.54 \pm 7.21) \mathrm{m} / \mathrm{s}$ & 0.181 \\
\hline \multirow{3}{*}{ MEDIAN } & $\mathrm{DSL}^{\mathrm{d}}$ & $(3.87 \pm 1.80) \mathrm{ms}$ & $(4.07 \pm 1.51) \mathrm{ms}$ & 0.743 \\
\hline & SNAP $^{\mathrm{e}}$ & $(17.27 \pm 12.39) \mu \mathrm{v}$ & $(26.23 \pm 19.21) \mu \mathrm{v}$ & 0.201 \\
\hline & $\mathrm{SNCV}^{\mathrm{f}}$ & $(40.73 \pm 12.41) \mathrm{m} / \mathrm{s}$ & $(42.42 \pm 12.46) \mathrm{m} / \mathrm{s}$ & 0.560 \\
\hline \multirow{3}{*}{ SURAL } & $\mathrm{DSL}^{\mathrm{d}}$ & $(5.84 \pm 1.66) \mathrm{ms}$ & $(4.52 \pm 1.16) \mathrm{ms}$ & 0.298 \\
\hline & SNAP $^{\mathrm{e}}$ & $(4.38 \pm 1.24) \mu \mathrm{v}$ & $(4.84 \pm 1.85) \mu \mathrm{v}$ & 0.325 \\
\hline & $\mathrm{SNCV}^{\mathrm{f}}$ & $(20.77 \pm 6.87) \mathrm{m} / \mathrm{s}$ & $(27.11 \pm 7.54) \mathrm{m} / \mathrm{s}$ & 0.756 \\
\hline
\end{tabular}

a. DML-Distal Motor Latency, b. CMAP-Compound Muscle Action Potential, c. MNCV-Motor Nerve Conduction Velocity, d. DSL-Distal Sensory Latency, e. SNAP-Sensory Nerve Action Potential, f. SNCV-Sensory Nerve Conduction Velocity, g. SD-Standard Deviation

Table.2 Comparison between baseline and follow up values of NCS parameters and HbA1c by paired test and Wilcoxon signed rank test among cases

\begin{tabular}{|c|c|c|c|c|}
\hline \multicolumn{2}{|c|}{ Parameters } & \multirow{2}{*}{$\begin{array}{l}\begin{array}{l}\text { Baseline value } \\
\left(\text { Mean } \pm \text { SD }^{\mathrm{g}}\right)\end{array} \\
(3.99 \pm 1.34) \mathrm{ms}\end{array}$} & \multirow{2}{*}{\begin{tabular}{|l}
$\begin{array}{l}\text { Follow-up value } \\
\left(\text { Mean } \pm \mathbf{S D}^{\mathbf{g}}\right)\end{array}$ \\
$(3.73 \pm 0.82) \mathrm{ms}$
\end{tabular}} & \multirow{2}{*}{\begin{tabular}{|l} 
p Value \\
0.241
\end{tabular}} \\
\hline \multirow{3}{*}{ MEDIAN } & $\mathrm{DML}^{\mathrm{a}}$ & & & \\
\hline & $\mathrm{CMAP}^{\mathrm{b}}$ & $(3.94 \pm 2.54) \mathrm{mv}$ & $(10.05 \pm 4.34) \mathrm{mv}$ & $<0.001 *$ \\
\hline & $\mathrm{MNCV}^{\mathrm{c}}$ & $(49.47 \pm 8.39) \mathrm{m} / \mathrm{s}$ & $(52.41 \pm 7.27) \mathrm{m} / \mathrm{s}$ & 0.192 \\
\hline \multirow{3}{*}{ TIBIAL } & $\mathrm{DML}^{\mathrm{a}}$ & $(5.18 \pm 0.90) \mathrm{ms}$ & $(5.37 \pm 1.18) \mathrm{ms}$ & 0.515 \\
\hline & $\mathrm{CMAP}^{\mathrm{b}}$ & $(3.07 \pm 3.26) \mathrm{mv}$ & $(7.12 \pm 4.79) \mathrm{mv}$ & $0.001 *$ \\
\hline & $\mathrm{MNCV}^{\mathrm{c}}$ & $(41.49 \pm 8.74) \mathrm{m} / \mathrm{s}$ & $(40.36 \pm 5.91) \mathrm{m} / \mathrm{s}$ & 0.595 \\
\hline \multirow{3}{*}{ MEDIAN } & $\mathrm{DSL}^{\mathrm{d}}$ & $(3.87 \pm 1.80) \mathrm{ms}$ & $(3.43 \pm 1.02) \mathrm{ms}$ & 0.352 \\
\hline & $\mathrm{SNAP}^{\mathrm{e}}$ & $(17.27 \pm 12.39) \mu \mathrm{v}$ & $(32.11 \pm 18.20) \mu \mathrm{v}$ & $<0.001 *$ \\
\hline & $\mathrm{SNCV}^{\mathrm{f}}$ & $(40.73 \pm 12.41) \mathrm{m} / \mathrm{s}$ & $(46.42 \pm 11.28) \mathrm{m} / \mathrm{s}$ & 0.003* \\
\hline \multirow{3}{*}{ SURAL } & $\mathrm{DSL}^{\mathrm{d}}$ & $(5.84 \pm 1.66) \mathrm{ms}$ & $(4.85 \pm 1.30) \mathrm{ms}$ & $0.019 *$ \\
\hline & SNAP $^{\mathrm{e}}$ & $(4.38 \pm 1.24) \mu v$ & $(7.36 \pm 3.69) \mu v$ & $<0.001 *$ \\
\hline & $\mathrm{SNCV}^{\mathrm{f}}$ & $(20.77 \pm 6.87) \mathrm{m} / \mathrm{s}$ & $(23.79 \pm 8.34) \mathrm{m} / \mathrm{s}$ & 0.095 \\
\hline \multicolumn{2}{|c|}{ Glycemic Status (HbA1c) } & $7.51 \pm 1.66$ & $6.98 \pm 1.42$ & 0.088 \\
\hline
\end{tabular}


Table.3 Comparison between change of values of NCS parameters and HbA1c among cases and controls by test and Mann Whitney test

\begin{tabular}{|c|c|c|c|c|}
\hline \multicolumn{2}{|c|}{ Change of parameters } & \multirow{2}{*}{$\begin{array}{l}\text { Change of values among } \\
\text { Cases (Mean } \pm \mathbf{S D}^{\mathbf{g}} \text { ) }\end{array}$} & \multirow{2}{*}{$\begin{array}{l}\begin{array}{l}\text { Change of values among } \\
\text { Controls }\left(\text { Mean } \pm \mathbf{S D}^{\mathbf{g}} \text { ) }\right.\end{array} \\
0.35 \pm 0.87\end{array}$} & \multirow{2}{*}{$\begin{array}{l}\text { p Value } \\
0.082\end{array}$} \\
\hline \multirow{3}{*}{ MEDIAN } & $\mathrm{DML}^{\mathrm{a}}$ & & & \\
\hline & $\mathrm{CMAP}^{\mathrm{b}}$ & $6.08 \pm 4.25$ & $-1.10 \pm 1.21$ & $<0.001 *$ \\
\hline & $\mathrm{MNCV}^{\mathrm{c}}$ & $2.94 \pm 8.38$ & $-2.20 \pm 7.17$ & 0.035* \\
\hline \multirow{3}{*}{ TIBIAL } & $\mathrm{DML}^{\mathrm{a}}$ & $0.24 \pm 1.53$ & $-0.05 \pm 0.82$ & 0.557 \\
\hline & $\mathrm{CMAP}^{\mathrm{b}}$ & $4.04 \pm 3.83$ & $-0.90 \pm 1.12$ & $<0.001 *$ \\
\hline & $\mathrm{MNCV}^{\mathrm{c}}$ & $-1.12 \pm 10.38$ & $-3.20 \pm 5.02$ & 0.400 \\
\hline \multirow{3}{*}{ MEDIAN } & $\mathrm{DSL}^{\mathrm{d}}$ & $-0.40 \pm 1.15$ & $0.00 \pm 1.12$ & 0.203 \\
\hline & SNAP $^{\mathrm{e}}$ & $14.80 \pm 13.77$ & $-12.90 \pm 17.85$ & $<0.001 *$ \\
\hline & $\mathrm{SNCV}^{\mathrm{f}}$ & $5.64 \pm 8.57$ & $-4.05 \pm 10.02$ & $0.001 *$ \\
\hline \multirow{3}{*}{ SURAL } & $\mathrm{DSL}^{\mathrm{d}}$ & $-0.80 \pm 1.91$ & $0.85 \pm 1.18$ & $0.002 *$ \\
\hline & SNAP $^{\mathrm{e}}$ & $2.98 \pm 2.45$ & $-0.45 \pm 0.69$ & $<0.001 *$ \\
\hline & $\mathrm{SNCV}^{\mathrm{f}}$ & $3.08 \pm 8.68$ & $-5.80 \pm 6.24$ & 0.013* \\
\hline \multicolumn{2}{|c|}{ Glycemic Status (HbA1c) } & $-0.48 \pm 0.77$ & $0.00 \pm 0.32$ & 0.008* \\
\hline
\end{tabular}

Table.4A Comparison of change of values of NCS parameters and HbA1c among three different groups of cases by ANOVA $^{\mathrm{h}}$ and Kruskal-Wallis test

\begin{tabular}{|c|c|c|c|}
\hline \multicolumn{2}{|c|}{ Change of Parameters } & \multirow{2}{*}{$\frac{\text { Groups }}{\text { Between groups }}$} & \multirow{2}{*}{$\frac{\text { p Value }}{0.001 *}$} \\
\hline \multirow{3}{*}{ MEDIAN } & $\mathrm{DML}^{\mathrm{a}}$ & & \\
\hline & $\mathrm{CMAP}^{\mathrm{b}}$ & Between groups & 0.730 \\
\hline & $\mathrm{MNCV}^{\mathrm{c}}$ & Between groups & 0.268 \\
\hline \multirow{3}{*}{ TIBIAL } & $\mathrm{DML}^{\mathrm{a}}$ & Between groups & 0.197 \\
\hline & $\mathrm{CMAP}^{\mathrm{b}}$ & Between groups & 0.746 \\
\hline & $\mathrm{MNCV}^{\mathrm{c}}$ & Between groups & 0.096 \\
\hline \multirow{3}{*}{ MEDIAN } & $\mathrm{DSL}^{\mathrm{d}}$ & Between groups & 0.110 \\
\hline & SNAP $^{\mathrm{e}}$ & Between groups & 0.292 \\
\hline & $\mathrm{SNCV}^{\mathrm{f}}$ & Between groups & 0.708 \\
\hline \multirow{3}{*}{ SURAL } & $\mathrm{DSL}^{\mathrm{d}}$ & Between groups & 0.858 \\
\hline & SNAP $^{\mathrm{e}}$ & Between groups & 0.287 \\
\hline & $\mathrm{SNCV}^{\mathrm{f}}$ & Between groups & 0.274 \\
\hline \multicolumn{2}{|c|}{ Glycemic Status (HbA1c) } & Between groups & 0.004* \\
\hline
\end{tabular}


Table.4B Post-hoc analysis of significant observations within groups

\begin{tabular}{|c|c|c|c|}
\hline Parameters & \multicolumn{2}{|c|}{ Within groups } & \multirow{2}{*}{$\begin{array}{l}\text { p Value } \\
0.294\end{array}$} \\
\hline \multirow{6}{*}{ NCS Parameters (MEDIAN DML) } & \multirow[t]{2}{*}{ Gr 1(n=13) } & Gr 2 & \\
\hline & & Gr 3 & $<0.001 *$ \\
\hline & $\operatorname{Gr} 2(n=8)$ & Gr 1 & 0.294 \\
\hline & & Gr 3 & 0.014* \\
\hline & $\operatorname{Gr} 3(n=4)$ & Gr 1 & $<0.001 *$ \\
\hline & & Gr 2 & $0.014 *$ \\
\hline \multirow{6}{*}{ Glycemic Status (HbA1c) } & \multirow[t]{2}{*}{ Gr 1(n=13) } & Gr 2 & 0.451 \\
\hline & & Gr 3 & 0.003* \\
\hline & \multirow[t]{2}{*}{ Gr 2(n=8) } & Gr 1 & 0.451 \\
\hline & & Gr 3 & $0.042 *$ \\
\hline & \multirow[t]{2}{*}{ Gr 3(n=4) } & Gr 1 & 0.003* \\
\hline & & Gr 2 & $0.042 *$ \\
\hline
\end{tabular}

Gupta et al., (1998) found significantly improved Median and Common Peroneal Nerve conduction velocity after 6 weeks of zinc (660 mg /day). Hayee et al., in 2005 found highly significant improvement of MNCV of both Median and Common Peroneal nerve after 6 weeks of Zinc therapy (660 mg /day) in patients of DN compared to controls, without any significant adverse effect. Previous studies did not explore any effect of zinc on sensory and other motor nerve conduction study parameters (latency and amplitude) other than MNCV.

The commonest neurophysiological abnormality in diabetes is reduction in the amplitude of motor or sensory action potential because of axonopathy (Mishra and Kalita, 2014). In a comparative SNC study done by Verma et al., (2013) there was a significant decrease of SNAP amplitude of Median, Radial, Ulnar, Superficial Peroneal and Sural nerves in patients with Non-Insulin Dependent Diabetes Mellitus even without symptoms of peripheral neuropathy and healthy volunteers (Verma et al., 2013). Another study showed significant decrease in amplitude and velocity in diabetes with increased latency of motor and sensory nerves compared to controls (Pandya et al., 2013). Decrease of Nerve Conduction Velocity (NCV) is one of the earliest neuropathic abnormalities in DM and may present at diagnosis in type 2 DM (Thomas and Eliasson, 1984).

Numerous studies show decreased serum zinc level in diabetes. High concentrations of glucose and other secretagogues decrease the islet cell labile zinc; and zinc concentration in islet cells were related to the synthesis, storage and secretion of insulin as shown by video fluorescence analysis (Zalewski et al., 1994). Low serum zinc level in diabetes has been attributed to inadequate absorption or increased urinary excretion or both (Chausmer, 1998).

In our study, we noted baseline HbA1c and value after 12 weeks in Cases and Controls. Baseline HbA1c value of Cases changed from $(7.51 \pm 1.66)$ to $(6.98 \pm 1.42)$ after 12 weeks, though this difference was statistically not significant $(p>0.05)$. But comparing the difference in values (decrement) from baseline to follow-up between Cases and Controls, it was found that there was statistically significant decrease of $\mathrm{HbAlc}$ in Cases $(0.48 \pm 0.77)$ compared to Controls $(0.00 \pm 0.32) ; \mathrm{p}=0.008$.

Comparing this change among three different groups of Cases, statistically significant difference $(p=0.004)$ was found for the decrease of HbA1c.Change in HbA1c (12 week-baseline $=\Delta \mathrm{HbA1c}$ ) was $-0.25 \pm 0.34,-0.56 \pm 0.25$ and-1.35 \pm 1.32 in Groups 1, 2 and 3 respectively, thereby showing the best response in Group 3.Thus patients with the longest disease duration had the best $\mathrm{HbA} 1 \mathrm{c}$ response to zinc.

Our study concurs well with previous studies done by Al-Maroof et al., (2006) and Afkhami-Ardekani et al., (2008). Similar reduction of HbA1c along with reduction of fasting plasma glucose, 2 hour post-prandial plasma glucose, total Cholesterol (TC) and TC/HDL ratio was also found (Gunasekara et al., 2011). In the same year, Farvid et al., (2011) also found significant reduction of $\mathrm{HbA} 1 \mathrm{c}$ and neuropathic score in type 2 diabetic patients by micronutrient supplementations. Similar results was also found by other workers in previous studies (Hussain 
et al., (2006), Parham et al., 2008), though the study by Niewoehner et al., (1986) did not find improvements in diabetes control.

Apart from improving neuropathy and glycemic status, zinc also has an important effect on improving nephropathy as shown by Farvid et al., (2005). Improvement of glycemic status and nephropathy was further supported by another study (Khan et al., 2013). Zinc also has some promising role in reduction of BP and lipid profile (Farvid et al., 2004a, Farvid et al., 2004b).

In our study, zinc therapy showed marked improvement on neurophysiological findings in DN as reflected by significant changes of NCS parameters when compared with their baseline value. The change (increment or decrement) of different NCS parameters from baseline to follow-up level showed significant difference among Cases and Controls for both motor and sensory parameters favoring Cases. Improvements of sensory nerve parameters were quite uniform and consistent. Apart from conduction velocity, it was the amplitude (both motor and sensory nerves) which showed highly significant change after zinc therapy. Not only NCS parameters, decrement of $\mathrm{HbA} 1 \mathrm{c}$ from baseline to follow-up was higher in Cases compared to Controls, which meant that zinc supplementation improved glycemic status in Cases. Comparing the changes (NCS parameters and glycemic status) among the three different groups of Cases, significant decline of Median latency (motor) and $\mathrm{HbAlc}$ level, suggesting these parameters, after zinc therapy, varied significantly according to duration of diabetes with the best response in those with the longest diabetes duration.

The present study is unique in that, we measured baseline and follow-up latency and amplitude (for both motor and sensory nerves) along with conduction velocity in patients with diabetic neuropathy who received zinc and compared the values those who did not receive zinc.

From this study we conclude that zinc is an extremely promising therapeutic modality in patients with diabetic neuropathy and zinc supplementation may contribute to improved glycemic outcomes in patients with DN. It is interesting that the Median DML and HbA1c improved most in those with the longest duration of diabetes. If these findings (improvement) can be confirmed by other studies, it is indeed promising, as established therapeutic modalities fail with increase in duration of diabetes.
More studies are required on a larger population preferably with measurement of serum zinc levels. Basic research on the exact mechanisms of the benefits of zinc in DN will expand our understanding further. Our observation that zinc supplementation also improves glycemic outcome is exciting and needs further research for confirmation and explanation.

\section{Conflict of interest}

None of the authors have potential conflicts of interest to disclose.

\section{References}

Afkhami-Ardekani, M., Karimi M, Mohammadi SM, Nourani F. Effect of Zinc sulfate supplementation on lipid and glucose in type 2 diabetic patients. Pak J Nutr 2008, 7:550-53.

Al-Maroof, R.A., and Al-Sharbatti SS. Serum Zinc levels in diabetic patients and effect of Zinc supplementation on glycemic control of type 2 diabetics. Saudi Medical Journal 2006, 27:34450.

Chausmer, AB: Zinc, insulin and diabetes. $J \mathrm{Am}$ CollNutr 1998, 17:109-15.

Diabetes: facts and figures. International Diabetes Federation. Available from: http://www.idf.org/about-diabetes/facts-figures.

Farvid, M.S., Homayouni F, Amiri Z, Adelmanesh F: Improving neuropathy scores in type 2 diabetic patients using micronutrients supplementation. Diabetes Research and Clinical Practice 2011, 93:86-94.

Farvid, M.S., Jalali M, Siassi F, Hosseini M: Comparison of the effects of vitamins and/or mineral supplementation on glomerular and tubular dysfunction in type 2 diabetes. Diabetes Care 2005, 28:2458-64.

Farvid, M.S., Jalali M, Siassi F, Saadat N, Hosseini M: The impact of vitamins and/or mineral supplementation on blood pressure in type 2 diabetes. J Am CollNutr 2004a, 23:272-79.

Farvid, M.S., Siassi F, Jalali M, Hosseini M, Saadat N: The impact of vitamin and/or mineral supplementation on lipid profiles in type 2 diabetes. Diabetes Research and Clinical Practice 2004b, 65:21-8.

Garg, V.K., Gupta R, Goyal RK. HypoZincemia in diabetes mellitus. J AssocPsysicians India 1994; 42: $720-21$. 
Gunasekara, P., Hettiarachchi M, Liyanage C, Lekamwasam S: Effects of Zinc and multimineral vitamin supplementation on glycemic and lipid control in adult diabetes. Diabetes, Metabolic Syndrome and Obesity: Targets and Therapy 2011, 4:53-60.

Gupta, R., Garg VK, Mathur DK, Goyal RK: Oral Zinc therapy in diabetic neuropathy. J Assoc Physicians India 1998, 46:939-42.

Hayee, M.A., Mohammad QD, Haque A: Diabetic neuropathy and Zinc therapy. Bangladesh Med Res Counc Bull 2005, 31:62-7.

Hussain, S.A., Khadim HM, Khalaf BH, Ismail SH, Hussein KI, and Sahib AS: Effects of melatonin and Zinc on glycemic control in type 2 diabetic patients poorly controlled with metformin. Saudi Med J 2006, 27:1483-88.

Isbir, T., Tamer L, Tayor A, Isbir M. Zinc, copper and magnesium in insulin dependent diabetes. Diabetes Res 1994; 26: 41-5.

Jayawardena, R., Ranasinghe P, Galappatthy P, Malkanthi R, Constantine G, Katulanda P. Effects of Zinc supplementation on diabetes mellitus: a systematic review and meta-analysis. Diabetol Metab Syndr 2012; 4:13-23.

Khan, M.I., Siddique KU, Ashfaq F, Ali W, Reddy HD, Mishra A: Effect of high-dose Zinc supplementation with oral hypoglycemic agents on glycemic control and inflammation in type-2 diabetic nephropathy patients. J Nat Sci Biol Med 2013; 4(2):336-40.

Khandelwal, P.O., Bhu N. A study of serum Zinc in uncontrolled diabetes. J Assoc Physicians India 1981; 29: 715-19.

Mishra, U.K., Kalita J. Clinical neurophysiology, $3^{\text {rd }}$ Edition Elsevier, a division of Reed Elsevier India Private Limited. 2014.

\section{How to cite this article:}

Sumana Gupta, Indira Maisnam, Tapobrata Guharay, Sandip Ghosh, Apurba Kumar Mukherjee and Anil Baran Singha Mahapatra. 2017. Zinc Supplementation Significantly Improves Neurophysiological and Glycemic Measures in Patients with Diabetic Neuropathy. Int.J.Curr.Res.Aca.Rev. 5(7), 61-69.

doi: https://doi.org/10.20546/ijcrar.2017.507.009
Niewoehner, C.B., Allen JI, Boosalis M, Levine AS, Morley JE. Role of Zinc supplementation in type II diabetes mellitus. Am J Med 1986; 81:63-8?

Pandya, N.H., Desai KS, Goswami TM, Patel VN, Mevada AK, Suthar MN. Neurophysiological changes in sensorimotor nerves in diabetes mellitus \& usefulness of nerve conduction studies for early diagnosis of diabetic neuropathy, IJBAR 2013; 04 (03):187-91.

Parham, M., Amini M, Aminorroaya A, Heidarian E: Effect of Zinc supplementation on microalbuminuria in patients with type 2 diabetes: A double blind, randomized, placebo-controlled, cross-over trial. Review of Diabetic Studies 2008, 5:102-09.

Stumvoll, M., Goldstein BJ, van Haeften TW. Type 2 diabetes: principles of pathogenesis and therapy. Lancet. 2005; 365:1333-1346. doi: 10.1016/S0140-6736(05)61032-X.

Thomas, P.K., Eliasson SG. Diabetic neuropathy. In: Dyck PJ, Thomas PK, Lambert EH, et al., eds. Peripheral neuropathy. Philadelphia: WB Saunders, 1984:1773-810.

Verma, A., Mahajan S, Khadayate P. Sensory Nerve Conduction Studies In Non-Insulin Dependent Diabetes Mellitus (NIDDM) Patients Without Symptoms Of Peripheral Neuropathy And Healthy Volunteers: A Comparative Study. IJBAP 2013; 2(1):158-62.

Zalewski, P., Millard S, Forbes I, Kapaniris O, Slavotinek S, Betts W, Ward A., and Lincoln S, Mahadevan I: Video image analysis of labile $\mathrm{Zn}$ in viable pancreatic islet cells using specific fluorescent probe for Zn. J Histochem Cytochem 1994, 42:877-84. 